\title{
Enhancing Value-Based Care With a Walk-in Clinic: A Primary Care Provider Intervention to Decrease Low Acuity Emergency Department Overutilization
}

\author{
Derek J. Baughman ${ }^{1}$, Abdul Waheed ${ }^{2,3}$, Muhammad N. Khan ${ }^{1}$, James M. Nicholson ${ }^{1}$ \\ 1. Family Medicine, WellSpan Good Samaritan Hospital, Lebanon, USA 2. Family Medicine, Wellspan Good Samaritan \\ Hospital, Lebanon, USA 3. Family and Community Medicine, Penn State University College of Medicine, Milton S. \\ Hershey Medical Center, Hershey, USA
}

Corresponding author: Derek J. Baughman, baughman.derek@gmail.com

\section{Abstract \\ Background}

Emergency department overutilization is a known contributor to the high per-capita healthcare cost in the United States. There is a knowledge gap regarding the substitution effect of walk-in clinic availability in primary care provider (PCP) offices and emergency department utilization (EDU). This study evaluates associations between PCP availability and EDU and analyzes the potential cost savings for health systems.

\section{Methods}

A retrospective cohort analysis compared low acuity EDU rates in established patients at a family medicine residency's PCP office before and after walk-in clinic implementation. The practice had 12 providers, 12 residents, and a patient panel of approximately 7,000-8,000. Inclusion criteria were met if patients were: (1) established with the PCP office, (2) had a low acuity emergency department (ED) visit (emergency index score level 4 or 5) $O R$ had a walk-in clinic visit at the family practice. ED visits were tracked from January 2018 to January 2020 and encounters were compared numbers to pre and post-implementation of a walk-in clinic. Cost savings for comparable management was estimated with average price differences for low acuity encounters in the ED versus clinic.

\section{Results}

Over the two-year timeframe, there were 10,962 total visits to the ED by family practice patients, 4,250 of these visits were low acuity. Despite gross monthly increases of EDU from 2018-2020, after implementation of a walk-in clinic in 2019, rates of total EDU decreased by $1.5 \%$ and low acuity utilization rates also decreased. The average annual patient census nearly doubled from 5,763 to 8,042. T-tests confirmed statistical significance with p-values $<0.05$. Average low acuity ED visits $(\$ 437)$ cost 4.9 times more than

Review began 01/21/2021 Review ended 02/08/2021 Published 02/11/2021

\section{() Copyright 2021}

Baughman et al. This is an open access article distributed under the terms of the Creative Commons Attribution License CC-BY 4.0., which permits unrestricted use, distribution, and reproduction in any medium, provided the original author and source are credited. comparable PCP office visits (\$91). Managing 2,387 patients in the walk-in clinic resulted in an estimated annual cost savings of $\$ 825,902$.

\section{Conclusion}

Extended walk-in availability in primary care offices provides non-ED capacity for low acuity management and might mitigate low acuity ED utilization while providing more cost-effective care. This study supports similarly described pre-hospital diversions in reducing ED over-utilization by increasing access to care. Higher levels of evidence are needed to establish causality.

Categories: Family/General Practice, Quality Improvement, Other Keywords: health economics outcomes research, emergency department utilization, family medicine, pcp, value based care, healthcare utilization, walk in clinic, pcp intervention, primary care medicine, health system research

\section{Introduction}

The prevalence of emergency department overutilization for non-urgent care is common and is known to contribute to the high cost of US healthcare. Although the causes of non-urgent ED visits are multifactorial, the literature has described many of the social determinant factors well. Higher proportions of patients with material needs like employment, food, and housing insecurities utilize the ED [1-2]. The prevalence of low acuity ED visits is disproportionally high in Medicaid populations that have an increased number of social determinants and/or health illiteracy [3-4]. In addition, Medicaid populations are more than twice as likely to have a higher number of low acuity ED visits if they have one or more barriers, notably, difficulties in acute primary care appointment scheduling, transportation, or availability of office hours) [5]. Although there is evidence that the use of healthcare resources like case management or patient-centered medical homes 
(PCMHs) can decrease emergency department utilization (EDU) [6], healthcare utilization is a standalone contributing factor for increased EDU. For example, having $>3$ primary care provider (PCP) visits per year, prior hospitalizations, increased age, female gender, and the presence of a prior mental health diagnosis increases ED overutilization [7]. In addition, patients with higher ED utilization (EDU) have increased healthcare utilization overall, including outpatient and hospital admissions. These patients also have a 2.2fold increased rate of mortality [8]. Patients with cancer, chronic non-cancer pain, and significant disabilities are also linked with EDU [4,9]. The reasons why patients feel the need to self-refer to the ED include, most commonly, the concern for personal health and the expectation of having these concerns evaluated. Other factors can include convenience, inaccessibility to primary care, lack of confidence in PCP, advice from others, and financial considerations [10].

Medical literature supports that some interventions might decrease lower acuity ED visits. Many studies have shown the mitigation of both low acuity EDU and cost of care via case management interventions $[2,4,6,11-17]$. The use of community health workers and patient education has also resulted in a significant benefit [2-3,6,16,18-21]. Other studies have analyzed various interventions that have been shown to decrease non-urgent EDU such as the creation of additional non-ED capacity (including walk-in hours or additional/extended business hours) [3,18,22]. The use of high-risk identifying prediction tools, interventions that followed patients beyond the referral process or simply having more involvement with the Patient-Centered Medical Home (PCMH) has shown to reduce cost and ED use [4,23-26]. Several studies demonstrate the cooperative effect of incorporating multiple interventions to decrease EDU $[3,6,25]$. While cost-sharing appears to reduce EDU [3], patient financial incentives seem to be not as effective [18,26]. Although some studies note equivocal rates of EDU reduction with diversion interventions [9,24], several studies have shown the success of pre-hospital diversions [27], including 911 telephone triaging and personally escorting patients from the ED to the clinic [18-19,21].

There is a paucity of analysis specifically on the use of walk-in clinic hours in PCP offices as an intervention for reducing low-acuity EDU. The purpose of this study was to evaluate the medical, financial, and logistical impact of providing walk-in clinic hours at a residency family practice site to manage acute medical conditions of a non-emergent nature and, in turn, decompress emergency department utilization in the health system. Considering the potential role of primary care interventions is an important step in addressing underlying causes of inflated per-capita health care costs since the impact of cost mitigation at the community level has conceivably exponential potential when applied to the state and national levels.

\section{Materials And Methods}

We performed a retrospective cohort study involving an urban PCP office in South Central Pennsylvania. The population in Lebanon, PA (a city of approximately 25,000), was predominantly Caucasian (58\%) with significant Hispanic (25\%) and Black (5\%) minorities. These population patterns are similar to the distribution of race in the 2010 US census [28]. Our cohort was a sample of this population: established patients at WellSpan North 4th Street Family Medicine Office in Lebanon, PA (one of the Good Samaritan Hospital's Family Medicine residency program PCP offices). "Established patient" was defined according to Medicare's definition - patients with a PCP visit within a historical three-year window [29]. Both our ED and PCP offices use the same electronic medical record (EMR) (Epic; Verona, WI), which allowed for the convenient generation of workbench reports for emergency room visit data by patients established at our practice. These data were obtained with IRB exemption for patients established at the practice from January 2015 to January 2020 in order to generate an established patient census from January 2018 to January 2020 (thus, for example, an established patient for the month of January in 2018 would have had a visit somewhere between January 2015 to January 2018 to meet the three-year window criteria).

Inclusion criteria for ED low acuity visits at Good Samaritan Hospital were according to the Agency for Healthcare Research and Quality Emergency Severity Index (ESI) scoring [30]. Low acuity was defined as ESI 4 or 5 and high acuity was defined as ESI 1-3. ED visits were captured from the affiliated Good Samaritan Hospital ED (only 0.8 miles from the North 4th Street PCP office). Walk-in clinic hours were on weekdays from 08:00 to 12:00 and monthly gross numbers were tracked in the EMR after their implementation in January 2019. Notably, only patients established at the practice (North 4th Street Family Medicine) were eligible to be seen in the walk-in clinic. These data were imported to Microsoft Excel (Microsoft Corporation, Redmond, WA) where 10,962 ED visits were analyzed from January 2018 to January 2020 alongside a monthly rolling census and total walk-in visit numbers (Table 1). In order to make a fair comparison between walk-in clinic hours and low acuity EDU, the low acuity visit numbers were adjusted to match the four-hour walk-in clinic hours timeframe of 08:00 to 12:00. This was termed “adjusted” EDU (essentially a sub-selection of the low acuity visits) where ED visits by clinic patients were only tabulated if the ED encounter was during the window 08:00-12:00). 


\begin{tabular}{|c|c|c|c|c|c|c|c|c|c|c|c|}
\hline \multirow[t]{2}{*}{ Month-Year } & $\begin{array}{l}\text { Total } \\
\text { High } \\
\text { Acuity }\end{array}$ & $\begin{array}{l}\text { Total } \\
\text { Low } \\
\text { Acuity }\end{array}$ & $\begin{array}{l}\text { Adjusted } \\
\text { LA EDU } \\
\text { visits }\end{array}$ & $\begin{array}{l}\text { Total } \\
\text { ED } \\
\text { visits }\end{array}$ & $\begin{array}{l}\text { Rolling } \\
\text { pts } \\
\text { census }\end{array}$ & $\begin{array}{l}\text { walk- } \\
\text { in } \\
\text { visits }\end{array}$ & $\begin{array}{l}\text { HA } \\
\text { EDU } \\
\text { rate }\end{array}$ & $\begin{array}{l}\text { LA } \\
\text { EDU } \\
\text { rate }\end{array}$ & $\begin{array}{l}\text { Adjusted } \\
\text { LA EDU } \\
\text { rate }\end{array}$ & $\begin{array}{l}\text { Total } \\
\text { EDU } \\
\text { rate }\end{array}$ & $\begin{array}{l}\text { Walk-in } \\
\text { visit rate }\end{array}$ \\
\hline & ESI 1-3) & \multicolumn{2}{|l|}{ (ESI 4-5) } & \multicolumn{2}{|c|}{$\begin{array}{l}\text { (established } \\
\text { patients only) }\end{array}$} & \multicolumn{4}{|c|}{ (rates are per 100 patients) } & & \\
\hline Jan-18 & 236 & 172 & 80 & 408 & 4423 & & 5.3 & 3.9 & 1.8 & 9.2 & \\
\hline Feb-18 & 214 & 168 & 81 & 382 & 4705 & & 4.5 & 3.6 & 1.7 & 8.1 & \\
\hline Mar-18 & 229 & 166 & 71 & 395 & 4998 & & 4.6 & 3.3 & 1.4 & 7.9 & \\
\hline Apr-18 & 221 & 146 & 66 & 367 & 5211 & & 4.2 & 2.8 & 1.3 & 7.0 & \\
\hline May-18 & 233 & 143 & 84 & 376 & 5460 & & 4.3 & 2.6 & 1.5 & 6.9 & \\
\hline Jun-18 & 191 & 125 & 45 & 316 & 5691 & & 3.4 & 2.2 & 0.8 & 5.6 & \\
\hline Jul-18 & 247 & 118 & 60 & 365 & 5937 & & 4.2 & 2.0 & 1.0 & 6.1 & \\
\hline Aug-18 & 228 & 140 & 51 & 368 & 6133 & & 3.7 & 2.3 & 0.8 & 6.0 & \\
\hline Sep-18 & 241 & 143 & 74 & 384 & 6351 & & 3.8 & 2.3 & 1.2 & 6.0 & \\
\hline Oct-18 & 260 & 166 & 88 & 426 & 6547 & & 4.0 & 2.5 & 1.3 & 6.5 & \\
\hline Nov-18 & 215 & 160 & 66 & 375 & 6759 & & 3.2 & 2.4 & 1.0 & 5.5 & \\
\hline Dec-18 & 268 & 181 & 72 & 449 & 6945 & & 3.9 & 2.6 & 1.0 & 6.5 & \\
\hline Jan-19 & 285 & 174 & 81 & 459 & 7118 & 41 & 4.0 & 2.4 & 1.1 & 6.4 & 0.6 \\
\hline Feb-19 & 255 & 169 & 80 & 424 & 7304 & 164 & 3.5 & 2.3 & 1.1 & 5.8 & 2.2 \\
\hline Mar-19 & 308 & 186 & 101 & 494 & 7478 & 157 & 4.1 & 2.5 & 1.4 & 6.6 & 2.1 \\
\hline Apr-19 & 322 & 184 & 91 & 506 & 7615 & 198 & 4.2 & 2.4 & 1.2 & 6.6 & 2.6 \\
\hline May-19 & 277 & 181 & 80 & 458 & 7761 & 183 & 3.6 & 2.3 & 1.0 & 5.9 & 2.4 \\
\hline Jun-19 & 286 & 179 & 71 & 465 & 7917 & 153 & 3.6 & 2.3 & 0.9 & 5.9 & 1.9 \\
\hline Jul-19 & 303 & 182 & 66 & 485 & 8033 & 180 & 3.8 & 2.3 & 0.8 & 6.0 & 2.2 \\
\hline Aug-19 & 321 & 169 & 86 & 490 & 8192 & 165 & 3.9 & 2.1 & 1.0 & 6.0 & 2.0 \\
\hline Sep-19 & 313 & 196 & 92 & 509 & 8356 & 226 & 3.7 & 2.3 & 1.1 & 6.1 & 2.7 \\
\hline Oct-19 & 286 & 186 & 93 & 472 & 8498 & 209 & 3.4 & 2.2 & 1.1 & 5.6 & 2.5 \\
\hline Nov-19 & 297 & 202 & 101 & 499 & 8655 & 211 & 3.4 & 2.3 & 1.2 & 5.8 & 2.4 \\
\hline Dec-19 19 & 310 & 180 & 78 & 490 & 8760 & 213 & 3.5 & 2.1 & 0.9 & 5.6 & 2.4 \\
\hline Jan-20 & 366 & 234 & 121 & 600 & 8855 & 287 & 4.1 & 2.6 & 1.4 & 6.8 & 3.2 \\
\hline Total pre-intervention & 2,783 & 1,828 & 838 & 4,611 & & & & & & & \\
\hline average & 232 & 152 & 69.8 & 384 & 5,763 & & 4.1 & 2.7 & 1.2 & 6.8 & \\
\hline Total post-intervention & 3,929 & 2,422 & 1,141 & 6,351 & & 2,387 & & & & & \\
\hline average & 302 & 186 & 87.8 & 489 & 8,042 & 184 & 3.8 & 2.3 & 1.1 & 6.1 & 2.3 \\
\hline $\begin{array}{l}\text { Difference of averages } \\
\text { pre and post-intervention }\end{array}$ & 70.3 & 34.0 & 17.9 & 104.3 & 2278.4 & & -0.3 & -0.4 & -0.2 & -0.7 & \\
\hline
\end{tabular}

TABLE 1: Summary of healthcare utilization data from January 2018 to January 2020 by established family practice patients

LA: low acuity; HA: high acuity; EDU: emergency department utilization 


\section{Cureus}

Gross numbers of total EDU, high acuity, low acuity, and time adjusted low acuity EDU were plotted in Microsoft Excel (Figure 1). To calculate rates of EDU, two methods were used. First, gross low acuity EDU was divided by the total EDU, and second, the low acuity EDU was divided by the rolling established patient census (Figure 2). T-tests compared monthly data, pre- and post-implementation of walk-in clinic hours, for low and high acuity EDU, adjusted low acuity EDU, walk-in clinic hours visits, average and rolling census numbers (Table 2), and p-values of $<0.05$ measured statistical significance.

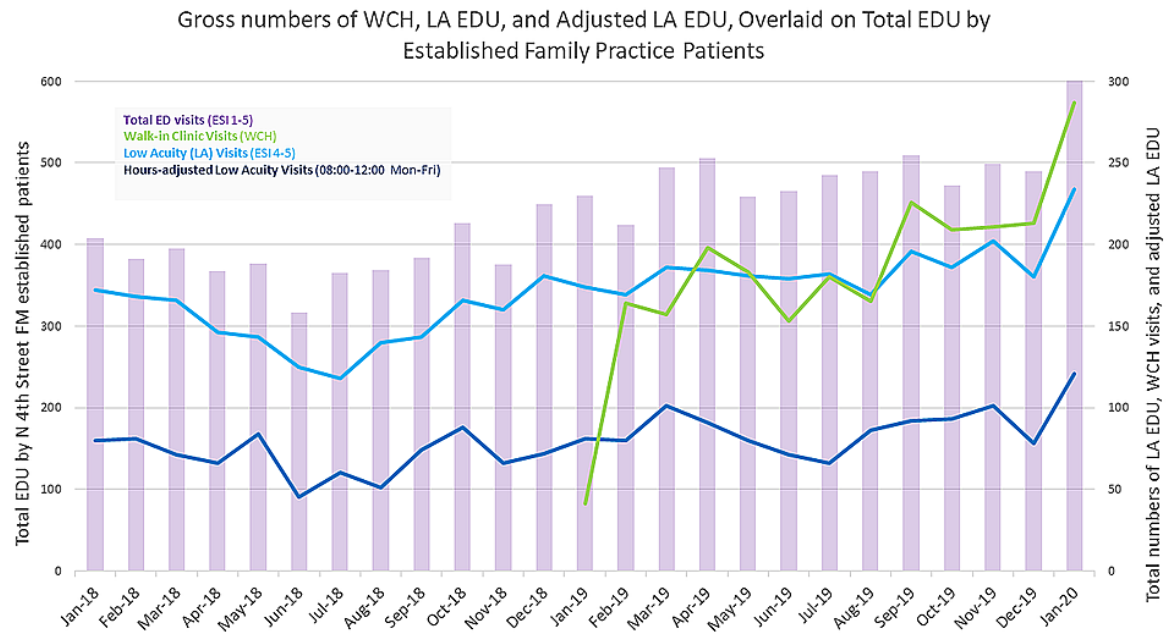

FIGURE 1: Gross numbers of WCH, LA EDU, and adjusted LA EDU, overlaid on total EDU established family practice patients

The dark blue line is the adjusted low acuity visit hours to match the walk-in clinic hour timeframe; essentially, these are all the low acuity ED visits (light blue) that happened only between 0800 and 1200 hours.

WCH: walk-in clinic hours; LA: low acuity; EDU: emergency department utilization

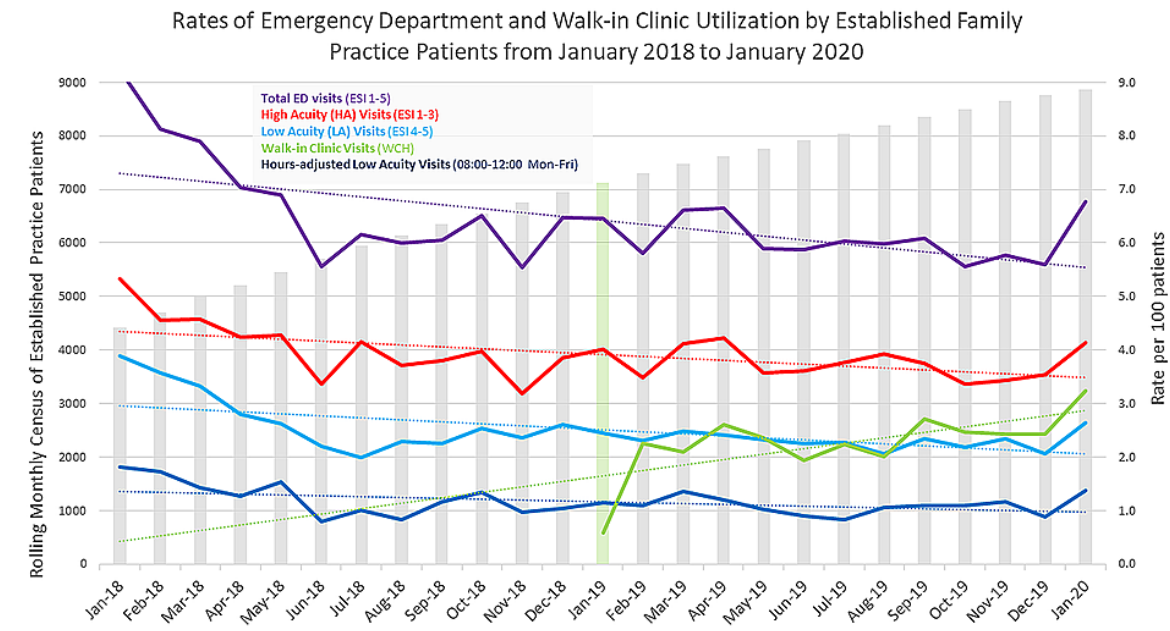

FIGURE 2: Rates of emergency department and walk-in clinic utilization by established family practice patients 


\section{Cureus}

\begin{tabular}{|c|c|c|c|c|}
\hline 2018 & 2019 & 2018-2019 & p-value & \\
\hline Adjusted monthly LA EDU & 69.8 & 87.8 & 1979 & $<0.05$ \\
\hline Monthly avg LA (aLA) & 152 & 186 & 170 & $<0.01$ \\
\hline Monthly avg HA (aHA) & 232 & 302 & 268 & $<0.01$ \\
\hline Monthly avg EDU (aEDU) & 384 & 489 & 438 & $<0.01$ \\
\hline Monthly avg census (aC) & 5,763 & 8,042 & 6948 & $<0.01$ \\
\hline tLA/tEDU & $39.6 \%$ & $38.1 \%$ & $-1.51 \%$ & \\
\hline aLA/aEDU & $39.6 \%$ & $38.1 \%$ & $-1.51 \%$ & \\
\hline tLA/aC & $31.7 \%$ & $30.1 \%$ & $-1.60 \%$ & \\
\hline $\mathrm{aLA} / \mathrm{aC}$ & $2.6 \%$ & $2.3 \%$ & $-0.33 \%$ & \\
\hline
\end{tabular}

TABLE 2: Summary of statistical analysis (T-tests comparing mean visit data) and calculation of utilization rates

LA: low acuity; EDU: emergency department utilization

Finally, cost comparisons of the WellSpan Medical group were obtained via population health data from the Emig Research Center, WellSpan York Hospital (Table 3). Of note, the cost data were derived nonempirically and represent the average low acuity visit cost in the ED (\$437) and corresponding average low acuity outpatient visit (\$91). The total monthly visit numbers of low acuity ED visits and walk-in clinic visits were multiplied by $\$ 437$ and $\$ 91$, respectively. Monthly dollar amounts were summed for the estimation of annual spending in the ED versus the walk-in clinic. Estimated cost savings were determined by taking the difference of the average ED and ambulatory visit cost (\$437-\$91), multiplying the result by the total number of patients seen in the walk-in clinic.

\begin{tabular}{|c|c|c|c|c|c|c|}
\hline Date & ESI 4 & ESI 5 & Total LA ED visits & Average level 1 ED visit $(\$ 437)^{1}$ & Total WCH visits & Ambulatory tier $1(\$ 91)^{2}$ \\
\hline 012018 & 160 & 12 & 172 & $\$ 75,164$ & & \\
\hline 022018 & 164 & 4 & 168 & $\$ 73,416$ & & \\
\hline 032018 & 148 & 18 & 166 & $\$ 72,542$ & & \\
\hline 042018 & 130 & 16 & 146 & $\$ 63,802$ & & \\
\hline 052018 & 123 & 20 & 143 & $\$ 62,491$ & & \\
\hline 062018 & 112 & 13 & 125 & $\$ 54,625$ & & \\
\hline 072018 & 99 & 19 & 118 & $\$ 51,566$ & & \\
\hline 082018 & 125 & 15 & 140 & $\$ 61,180$ & & \\
\hline 092018 & 128 & 15 & 143 & $\$ 62,491$ & & \\
\hline 102018 & 149 & 17 & 166 & $\$ 72,542$ & & \\
\hline 112018 & 144 & 16 & 160 & $\$ 69,920$ & & \\
\hline 122018 & 169 & 12 & 181 & $\$ 79,097$ & & \\
\hline 012019 & 158 & 16 & 174 & $\$ 76,038$ & 41 & $\$ 3,731$ \\
\hline 022019 & 155 & 14 & 169 & $\$ 73,853$ & 164 & $\$ 14,924$ \\
\hline 032019 & 176 & 10 & 186 & $\$ 81,282$ & 157 & $\$ 14,287$ \\
\hline 042019 & 164 & 20 & 184 & $\$ 80,408$ & 198 & $\$ 18,018$ \\
\hline 052019 & 162 & 19 & 181 & $\$ 79,097$ & 183 & $\$ 16,653$ \\
\hline
\end{tabular}




\section{Cureus}

$\begin{array}{|lllllll|}062019 & 173 & 6 & 179 & \$ 78,223 & 153 & \$ 13,923 \\ 072019 & 169 & 13 & 182 & \$ 79,534 & 180 & \$ 16,380 \\ 082019 & 159 & 10 & 169 & \$ 73,853 & 165 & \$ 15,015 \\ 092019 & 180 & 16 & 196 & \$ 85,652 & 226 & \$ 20,566 \\ 102019 & 169 & 17 & 186 & \$ 81,282 & 209 & \$ 19,019 \\ 112019 & 185 & 17 & 202 & \$ 88,274 & 211 & \$ 19,201 \\ 122019 & 166 & 14 & 180 & \$ 78,660 & 213 & \$ 19,383 \\ 012020 & 221 & 13 & 234 & \$ 102,258 & 287 & \$ 26,117 \\ \text { Total 2018-2019 } & 3888 & 362 & 4250 & \$ 1,857,250 & 2387 & \$ 217,217 \\ \text { average 2018 } & 138 & 15 & 152 & \$ 66,570 & & \$ 217,217 \\ \text { total 2019 } & 2237 & 185 & 2422 & \$ 1,058,414 & 2387 & \$ 16,709 \\ \text { average 2019 } & 172 & 14 & 186 & \$ 81,416 & 184 & \\ & & & & \$ .9 & \end{array}$

\section{TABLE 3: Cost-savings projection of walk-in clinic implementation}

1. The average cost of a Good Samaritan Hospital emergency Level 1 visit (CPT code: 99281) was \$437.

2. The average cost for a WellSpan Med Group established patient for a Tier 1 visit was either $\$ 68$ (CPT code: 99212 ) or $\$ 114$ (CPT code: 99213 ). The average of $\$ 68$ and $\$ 114$ is $\$ 91$.

3. Calculation for the average cost difference between a WCH and LA ED visit: avg Level 1 ED visit / avg ambulatory visit

4. Calculation for estimated cost savings in 2019 due to WCH: total WCH visits $2019 \times$ (\$437-\$91)

Source: Epic EMR workbench reports with Emig research center average billing cost data for low acuity visits. Cost estimations from the WellSpan medical group are average billing data for equivalent low acuity visit costs in the ED vs the ambulatory setting.

WCH: walk-in clinic hours; LA: low acuity; EDU: emergency department utilization; CPT: current procedural terminology

\section{Results}

The established office census nearly doubled and the average monthly census increased from 5,763 in 2018 to 8,042 in 2019 (Table 1). The gross numbers of total EDU (both high and low acuity EDU) increased from January 2018 to January 2020 (Figure 1), with an average monthly total EDU (tEDU) increasing from 384 to 480 , respectively. Gross low acuity EDU increased by an average difference of 34 patients per month; walk-in clinic hours adjusted low acuity EDU numbers increased on average by 10 patients per month, however, calculated rates of low acuity EDU decreased (when both denominators of tEDU and per 100 patients were used, Figure 2) and total low acuity EDU decreased by $1.5 \%$ (Table 2). Rates had a negative correlation coefficient $(\mathrm{r} 2=0.43)$.

Walk-in clinic hours visit numbers eventually exceeded total low acuity ED visits after September 2019, however, from January 2019 to January 2020, the average difference in visits per day between walk-in clinic hours and low acuity total EDU was only 2.7 patients. On average, in 2019, there were 95 more patients per month seen in walk-in clinic hours than seen at hours-adjusted low acuity EDU (monthly avg walk-in clinic hours $=184$, avg hours-adjusted low acuity EDU $=88$ ). A comparison of monthly mean visits from January 2018 to January 2020 between EDU and walk-in clinic hours were statistically significant (Appendix).

The average total estimated monthly costs for EDU and walk-in clinic hours for 2019 were $\$ 81,416$ and $\$ 16,709$ respectively (Table 3 ). Thus, in 2019 , an estimated average low acuity visit in the ambulatory setting was approximately $1 / 5$ th (20.4\%) as expensive as a comparable low acuity ED visit. USD 825,902 was the projected cost savings by seeing 2,387 patients in the clinic (instead of the ED). 


\section{Discussion}

First, our analysis demonstrates a statistically significant association between increased availability of walk-in clinic hours and lower rates of low acuity EDU in established patients. Although not causative, the association of provider availability and decreased utilization is consistent with recent literature describing the creation of additional non-ED capacity to decrease EDU [3,18,22]. This has also been shown to increase follow-up at PCMHs [4,24-25].

Second, low acuity care in the ambulatory setting was more cost-effective, and at WellSpan, it was about $1 / 5$ th the cost. Despite the gross simplification, conceivably, without adding a single physician or staff member, the North 4 th Street clinic saved $\$ 825,902$ by seeing low acuity patients in the walk-in clinic (Table 3). Explained hypothetically, if the 2387 patients seen in the walk-in clinic in 2019 had gone instead to the ED, that estimated cost would be $\$ 437$ x 2387 or $\$ 1,043,119$ (when in actuality, the comparative annual ambulatory total cost was $\$ 217,217$ ). The authors recognize this is not a formal cost-effective analysis (as access to payer data was not available), nonetheless, it is reasonable to conclude the frugality of ambulatory management given comparable management severity.

Third, it took only a small amount of time for walk-in clinic numbers to exceed low acuity EDU numbers. After the implementation of walk-in clinic hours, it took only six months for the number of walk-in clinic visits to exceed the total number of low acuity EDU visits (Figure 1). This comparison becomes even more meaningful when hours of EDU are adjusted to match low acuity EDU visit numbers to the 08:00-12:00 walkin clinic hours window. When only 08:00-12:00 low acuity visits were counted, the comparison to walk-in numbers is dramatic: more than double the number of patients were seen in walk-in just one month after implementation.

Fourth, facilitating lower acuity patient visits in the clinic mitigates the consumption of ED physician resources and frees up the ED for truly emergent patients. We describe this as 'decompression' of the ED. Decompression is an indirect effect of managing illness acuity in the appropriate clinical setting. The result of this appropriate alternative - decompressive outpatient management - enables ED providers to focus their attention on triaging the sickest patients while ensuring appropriate resources are available for urgent and emergent cases.

Finally, our study demonstrated a positive association between walk-in clinic availability and our practice census. We know that PCP follow-up $[3-4,6,25]$ and office education $[2-3,6,16,19,21]$ are investments that ultimately enhance value-based care by reducing unnecessary EDU. Thus, investing in PCP access via interventions like walk-in clinic hours has the feed-forward effect of enhancing PCP follow-up and the subsequent office education thereof. Accordingly, there was likely a delayed but potentially exponential effect of non-ED capacity that contributed to the doubling of our office census in 2019. Especially for patients with complex care needs, PCMH has consistently shown to both strengthen itself and mitigate known determinants to reduce cost and EDU [3,15]. As offering alternative treatment options has demonstrated a diversion of low acuity visits from the ED to the PCP, there is a potential for augmenting further public health benefits such as preventive care $[2,19,21]$. We are interested in continuing to follow practice data to support this hypothesis.

Although there is literature on ED utilization and super-utilization, the data are limited when it comes to connecting the dots between clinic patient panels and their respective EDU. Our study specifically investigated this concept and came across a challenge of defining the meaningful denominator and numerator to reflect the outcome. We knew that in the rate equation (low acuity EDU/total established patients), 'low acuity EDU' was the obvious numerator. The choice for denominator was a trial and error process but we ultimately chose 'Total established patients' to reflect the impact of walk-in clinic hours on building patient census (as this is the desired effect on a PCMH in implementing walk-in clinic hours). However, we recognize that using the total number of established patients may blur the association of decreasing low acuity EDU rates by "diluting” the numerator. Are walk-in clinic hours causing a decrease in the rate of EDU by providing an appropriate, yet more affordable, alternative venue? Or, are walk-in clinic hours causing an increasing rolling patient census that confounds the association with low acuity EDU rate reduction (i.e. a dilution of the numerator)? This is difficult to conclude, but what provides support to the former (decreasing the rate of low acuity EDU) is considering the correlation plots. When walk-in clinic hours are similarly converted to a rate (walk-in clinic hours/total rolling census), the correlation is positive (as expected with increasing numbers of walk-in visits). Conversely, even when low acuity EDU is adjusted to the 08:00-12:00 timeframe (adjusted low acuity EDU/total established patients), the correlation remains negative (decreased numbers of low acuity EDU in comparison to total established patients).

We recognize several limitations. Notable is the analysis of cost. It is difficult to cross-tabulate payment data for ESI 4-5 visits. After consulting payment experts in our health system, the authors felt that average visit cost data was an appropriate equivalent for financially quantifying low acuity EDU. More importantly, we feel this highlights the difficulty of obtaining such numbers since what is billed and what is paid is quite variable and is very hard to quantify (even for billing departments at the health system level). We recognize this limits the strength of cost-association, but does not promote the ignorance of cost-effective claims made in the discussion. We also recognize that our ability to draw conclusions regarding social determinants 


\section{Cureus}

of health, notably, access to care, is also limited by minimal demographic data. Social factors (age, race/ethnicity, payer type, comorbid conditions, and other risk factors) could better define the population and augment value-based care (VBC) arguments.

In the future, we plan to study how billing data acquisition highlights larger issues in certain reimbursement models within health systems. Despite proving a clear cost-benefit to society, there is actually a disincentive for hospitals operating in a fee for service (FFS) model to endorse walk-in clinic hours as a cost mitigation strategy (since the reimbursement relies on what is billed, not recuperated savings). In FFS, there is less incentive for encouraging patients to use ambulatory venues (like walk-in clinic hours) for low acuity problems when the hospital can hypothetically bill nearly five times more by seeing the same patient in the ED. However, steering policy efforts toward supporting an ambulatory focus for low acuity EDU in FFS models may be soon obsolete since most modern health systems are progressing toward VBC. Thus, for health systems operating in a VBC model, it is favorable to increase the use of ambulatory care for low acuity visits to offload overutilization of the ED. Moreover, with VBC, the per capita savings with ambulatory management is a sensible financial incentive to support the model. It is more cost-effective, enhances the opportunity for preventive care, and increases follow-up at PCHMs.

\section{Conclusions}

The implementation of walk-in clinic hours was associated with decreased rates of low acuity ED utilization in patients at our family medicine practice. In our health system, a low acuity ambulatory visit costs nearly $1 / 5$ th that of a comparable ED visit, demonstrating the potential for per capita cost reduction. These findings support the medical literature and may lead to improved follow-up within PCMHs. As value-based care is the progression of modern healthcare, efforts to facilitate increased ambulatory management for low acuity care is a financial incentive. Future research should measure the intervention effect across multiple healthcare sites where randomization to offering or not offering walk-in clinic hours could measure relative changes in EDU to conclude causality rather than association. Such evidence could support executive decisions to increase the implementation of non-ED capacity (especially walk-in clinics at PCP sites) for low acuity care in health systems to enhance the model of value-based care.

\section{Appendices}

\section{T-Test: Two-Sample Assuming Equal Variances}

Mean

Variance

Observations

Pooled Variance

Hypothesized Mean Difference

df

t Stat

$\mathrm{P}(\mathrm{T}<=\mathrm{t})$ one-tail

t Critical one-tail

$\mathrm{P}(\mathrm{T}<=\mathrm{t})$ two-tail

t Critical two-tail

T-Test: Two-Sample Assuming Equal Variances

Mean

Variance

Observations

Pooled Variance

Hypothesized Mean Difference

df

\section{Rolling Census \\ 2018 \\ 5763.333333 \\ 674418.2424 \\ 12 \\ 491017.6276 \\ 0 \\ 23 \\ $-8.122054603$ \\ 1.65233E-08 \\ 1.713871528 \\ 3.30466E-08 \\ 2.06865761}

2019

8041.692308

322900.3974

13

\section{Total EDU}

2018

2019

384.25

488.5384615

1124.022727

1675.102564

12

13

1411.542642

0 


\section{Cureus}

\begin{tabular}{|c|c|c|}
\hline t Stat & -6.93396355 & \\
\hline $\mathrm{P}(\mathrm{T}<=\mathrm{t})$ one-tail & $2.27525 \mathrm{E}-07$ & \\
\hline t Critical one-tail & 1.713871528 & \\
\hline$P(T<=t)$ two-tail & 0.00000046 & \\
\hline t Critical two-tail & 2.06865761 & \\
\hline \multirow[t]{2}{*}{ t-Test: Two-Sample Assuming Equal Variances } & HA EDU & \\
\hline & 2018 & 2019 \\
\hline Mean & 231.9166667 & 302.2307692 \\
\hline Variance & 440.2651515 & 728.1923077 \\
\hline Observations & 12 & 13 \\
\hline Pooled Variance & 590.4880156 & \\
\hline Hypothesized Mean Difference & 0 & \\
\hline df & 23 & \\
\hline t Stat & -7.228183829 & \\
\hline $\mathrm{P}(\mathrm{T}<=\mathrm{t})$ one-tail & 1.16801E-07 & \\
\hline t Critical one-tail & 1.713871528 & \\
\hline$P(T<=t)$ two-tail & 2.33603E-07 & \\
\hline t Critical two-tail & 2.06865761 & \\
\hline \multirow[t]{2}{*}{ t-Test: Two-Sample Assuming Equal Variances } & LA EDU & \\
\hline & 2018 & 2019 \\
\hline Mean & 152.3333333 & 186.3076923 \\
\hline Variance & 379.8787879 & 292.5641026 \\
\hline Observations & 12 & 13 \\
\hline Pooled Variance & 334.3232999 & \\
\hline Hypothesized Mean Difference & 0 & \\
\hline df & 23 & \\
\hline t Stat & -4.641520188 & \\
\hline $\mathrm{P}(\mathrm{T}<=\mathrm{t})$ one-tail & $5.687 \mathrm{E}-05$ & \\
\hline t Critical one-tail & 1.713871528 & \\
\hline$P(T<=t)$ two-tail & 0.00011374 & \\
\hline t Critical two-tail & 2.06865761 & \\
\hline \multirow[t]{2}{*}{ t-Test: Two-Sample Assuming Equal Variances } & Adjusted LA EDU & \\
\hline & 2018 & 2019 \\
\hline Mean & 69.83333333 & 85 \\
\hline Variance & 170.8787879 & 121.2727273 \\
\hline Observations & 12 & 12 \\
\hline Pooled Variance & 146.0757576 & \\
\hline Hypothesized Mean Difference & 0 & \\
\hline df & 22 & \\
\hline
\end{tabular}




\section{Cureus}

t Stat

$\mathrm{P}(\mathrm{T}<=\mathrm{t})$ one-tail

t Critical one-tail

$\mathrm{P}(\mathrm{T}<=\mathrm{t})$ two-tail

t Critical two-tai
$-3.073807695$

0.002777339

1.717144374

0.005554679

2.073873068

\section{TABLE 4: T-tests comparisons of utilization data}

tLA: total low acuity; aLA: average low acuity; tHA: total high acuity; aHA: average high acuity; tEDU: total emergency department utilization; aEDU: average emergency department utilization

\section{Additional Information \\ Disclosures}

Human subjects: Consent was obtained or waived by all participants in this study. WellSpan Health Institutional Review Board issued approval N/A. STUDY TITLE: [1716884-1] Enhancing Value-Based Care with Walk-in Clinic: A Primary Care Provider Intervention to Decrease Low Acuity Emergency Department Over- Utilization ACTION: DETERMINATION OF NOT RESEARCH DECISION DATE: February 4, 2021 Thank you for your submission of New Project materials for this research study. The WellSpan Health IRB has determined this project does not meet the definition of human subject research and, according to federal regulations, is not under the purview of the WellSpan Health IRB. No additional actions are necessary and you may start your project. Animal subjects: All authors have confirmed that this study did not involve animal subjects or tissue. Conflicts of interest: In compliance with the ICMJE uniform disclosure form, all authors declare the following: Payment/services info: All authors have declared that no financial support was received from any organization for the submitted work. Financial relationships: All authors have declared that they have no financial relationships at present or within the previous three years with any organizations that might have an interest in the submitted work. Other relationships: All authors have declared that there are no other relationships or activities that could appear to have influenced the submitted work.

\section{Acknowledgements}

Data acquisition was completed with the help of Julie Roth, Rebecca Caldwell, and the Epic Project-One team for WellSpan Health. Theodore Bell and the Emig Research Center provided an advisory role in statistical analysis. Kathryn Baughman provided an integral role in both data organization and literature review. Author contributions: AW and DB conceived the project conceptual framework. DB orchestrated data acquisition, ran the statistical analysis, drafted the original manuscript, completed the literature review, and served as team leader of this project. AW, JN, and MNK were integral to the data presentation and project mentorship and were editors of the final manuscript.

\section{References}

1. Malecha PW, Williams JH, Kunzler NM, Goldfrank LR, Alter HJ, Doran KM: Material needs of emergency department patients: a systematic review. Acad Emerg Med. 2018, 25:330-359. 10.1111/acem.13370

2. Moe J, Kirkland SW, Rawe E, Ospina MB, Vandermeer B, Campbell S, Rowe BH: Effectiveness of interventions to decrease emergency department visits by adult frequent users: a systematic review. Acad Emerg Med. 2017, 24:40-52. 10.1111/acem.13060

3. Flores-Mateo G, Violan-Fors C, Carrillo-Santisteve P, Peiró S, Argimon J-M: Effectiveness of organizational interventions to reduce emergency department utilization: a systematic review. PLoS One. 2012, 7:0035903. 10.1371/journal.pone.0035903

4. Wong CK, Orielly CM, Teitge BD, et al.: The characteristics and effectiveness of interventions for frequent emergency department utilizing patients with chronic noncancer pain: a systematic review. Acad Emerg Med. 2020, 27:742-752. 10.1111/acem.13934

5. Cheung PT, Wiler JL, Lowe RA, Ginde AA: National study of barriers to timely primary care and emergency department utilization among Medicaid beneficiaries. Ann Emerg Med. 2012, 60:4-10. 10.1016/j.annemergmed.2012.01.035

6. Heede KVD, Voorde CVD: Interventions to reduce emergency department utilization: a review of reviews . Health Policy. 2016, 120:1337-1349. 10.1016/j.healthpol.2016.10.002

7. Soril LJ, Leggett LE, Lorenzetti DL, Noseworthy TW, Clement FM: Characteristics of frequent users of the emergency department in the general adult population: a systematic review of international healthcare systems. Health Policy. 2016, 120:452-461. 10.1016/j.healthpol.2016.02.006

8. Moe J, Kirkland S, Ospina MB, et al.: Mortality, admission rates and outpatient use among frequent users of emergency departments: a systematic review. Emerg Med J. 2015, 33:230-236. 10.1136/emermed-2014204496

9. Dépelteau A, Racine-Hemmings F, Lagueux É, Hudon C: Chronic pain and frequent use of emergency 
department: a systematic review. Am J Emerg Med. 2019, 38:358-363. 10.1016/j.ajem.2019.158492

10. Kraaijvanger N, Leeuwen HV, Rijpsma D, Edwards M: Motives for self-referral to the emergency department: a systematic review of the literature. BMC Health Serv Res. 2016, 16:685. 10.1186/s12913-0161935-z

11. Iovan S, Lantz PM, Allan K, Abir M: Interventions to decrease use in prehospital and emergency care settings among super-utilizers in the United States: a systematic review. Med Care Res Rev. 2019, 77:99111. 10.1177/1077558719845722

12. Joo J, Liu M: Case management effectiveness in reducing hospital use: a systematic review . Int Nurs Rev. 2016, 64:296-308. 10.1111/inr.12335

13. Joo JY, Huber DL: Case management effectiveness on health care utilization outcomes: a systematic review of reviews. West J Nurs Res. 2018, 41:111-133. 10.1177/0193945918762135

14. Korczak V, Shanthosh J, Jan S, Dinh M, Lung T: Costs and effects of interventions targeting frequent presenters to the emergency department: a systematic and narrative review. BMC Emerg Med. 2019, 19:83. 10.1186/s12873-019-0296-4

15. Raven MC, Kushel M, Ko MJ, Penko J, Bindman AB: The effectiveness of emergency department visit reduction programs: a systematic review. Ann Emerg Med. 2016, 68:467-483. 10.1016/j.annemergmed.2016.04.015

16. Soril LJJ, Leggett LE, Lorenzetti DL, Noseworthy TW, Clement FM: Reducing frequent visits to the emergency department: a systematic review of interventions. PLoS One. 2015, 10:0123660. 10.1371/journal.pone.0123660

17. Jack HE, Arabadjis SD, Sun L, Sullivan EE, Phillips RS: Impact of community health workers on use of healthcare services in the united states: a systematic review. J Gen Intern Med. 2016, 32:325-344. 10.1007/s11606-016-3922-9

18. Morgan SR, Chang AM, Alqatari M, Pines JM: Non-emergency department interventions to reduce ED utilization: a systematic review. Acad Emerg Med. 2013, 20:969-985. 10.1111/acem.12219

19. Doran KM, Colucci AC, Hessler RA, et al.: An intervention connecting low-acuity emergency department patients with primary care: effect on future primary care linkage. Ann Emerg Med. 2013, 61:312-321. 10.1016/j.annemergmed.2012.10.021

20. Grossman LK, Rich LN, Johnson C: Decreasing nonurgent emergency department utilization by Medicaid children. Pediatrics. 1998, 102:20-24. 10.1542/peds.102.1.20

21. Krumperman K, Weiss S, Fullerton L: Two types of prehospital systems interventions that triage low-acuity patients to alternative sites of care. South Med J. 2015, 108:381-386.

22. Barzin A, Seybold OC, Page C: Integrating an urgent care clinic into an academic family medicine practice . Fam Med. 2020, 52:440-443. 10.22454/FamMed.2020.933051

23. Karam G, Radden Z, Berall LE, Cheng C, Gruneir A: Efficacy of emergency department-based interventions designed to reduce repeat visits and other adverse outcomes for older patients after discharge: a systematic review. Geriatr Gerontol Int. 2015, 15:1107-1117. 10.1111/ggi.12538

24. Shane DM, Nguyen-Hoang P, Bentler SE, Damiano PC, Momany ET: Medicaid health home reducing costs and reliance on emergency department. Med Care. 2016, 54:752-757. 10.1097/mlr.0000000000000555

25. Hughes JM, Freiermuth CE, Shepherd-Banigan M, et al.: Emergency department interventions for older adults: a systematic review. J Am Geriatr Soc. 2019, 67:1516-1525. 10.1111/jgs.15854

26. Bradley CJ, Neumark D, Walker LS: The effect of primary care visits on other health care utilization: a randomized controlled trial of cash incentives offered to low income, uninsured adults in Virginia. J Health Econ. 2018, 62:121-133. 10.1016/j.jhealeco.2018.07.006

27. Kirkland SW, Soleimani A, Rowe BH, Newton AS: A systematic review examining the impact of redirecting low-acuity patients seeking emergency department care: is the juice worth the squeeze?. Emerg Med J. 2018, 36:97-106. 10.1136/emermed-2017-207045

28. A brief history and description of Lebanon. (2020). Accessed: March 15, 2020: http://www.lebanonpa.org/Pages/AboutLebanon.aspx.

29. Dept. of HHS Centers for Medicare \& Medicaid Services. Evaluation and management services . (2017). https://www.cms.gov/Medicare/Medicare-Fee-for-Service-Payment/PhysicianFeeSched/Evaluation-andManagement-Visits.

30. Gilboy N, Tanabe P, Travers DA, Rosenau AM, Eitel DR: Emergency Severity Index Implementation Handbook. 2005. 